\title{
LA ALFABETIZACIÓN Y SUS PROMESAS ${ }^{1}$
}

\section{A ALFABETIZAÇÃO E SUAS PROMESSAS}

\author{
RODRÍGUEZ, Lidia Mercedes²
}

\section{RESUMEN}

En este trabajo se aborda lo que se plantea como una tensión en el campo de la educación popular y en el propio discurso de Paulo Freire. De modo sintético se podría plantear como la tensión entre dos horizontes de transformación del espacio educativo: el que pone el énfasis en el reconocimiento y jerarquización de los saberes populares; y el que se ubica más en la lógica de la educación moderna, que enfatiza la distribución del conocimiento socialmente acumulado. En el marco de esa problemática general y compleja, se analizan aspectos del debate que se sostuvo en Guinea Bissau sobre la lengua en que debía realizarse la alfabetización: Freire proponía el criollo, conformado por la vinculación del portugués con los idiomas naturales, mientras que Mário Cabral, responsable político de la reconstrucción educativa en Guinea Bissau decidió que se realizara en portugués. Se analizan luego los supuestos implícitos en cada una de esas propuestas, poniendo en tensión la afirmación de que es sólo en la lengua materna donde reside el proyecto emancipatorio, y también discutiendo una concepción del lenguaje que lo reduciría a su función instrumental.

PalabRAS Clave: Educación popular; Saberes; Alfabetización; Historia de la educación

\section{ResUmo}

Neste trabalho se aborda o que se propõe como uma tensão no campo da educação popular e no próprio discurso de Paulo Freire. De modo sintético, pode-se enfocar como a tensão entre dois horizontes de transformação do espaço educativo: o que destaca o reconhecimento e a hierarquização dos saberes populares; e o que se situa mais na lógica da educação moderna, que enfatiza a distribuição do conhecimento socialmente acumulado. No marco dessa problemática geral e complexa, analisam-se aspectos do debate que se manteve em Guiné-Bissau sobre a língua em que devia realizar-se a alfabetização: Freire propunha o crioulo, conformado pela vinculação do português com os idiomas naturais, enquanto Mário Cabral, responsável político pela reconstrução educativa na Guiné-Bissau decidiu que se realizasse em português. Em seguida, são analisados os pressupostos implícitos em cada uma dessas propostas, colocando em tensão a afirmação de que é somente na língua materna onde reside o projeto emancipatório, e também discutindo uma concepção da linguagem que o reduziria a sua função instrumental.

\footnotetext{
${ }^{1}$ Versión corregida de una ponencia presentada en el $\mathrm{V}$ encuentro internacional giros teóricos. Lenguaje, transgresión y fronteras. IISUE - UNAM. 21 al 24 de febrero de 2012. La misma se publicó en: De Alba, A. (2012) IV. Encuentro internacional Giros Teóricos. Lenguaje, transgresión y fronteras. Ponencias, México: UNAM.

${ }^{2}$ Profesora de la Universidad de Buenos Aires - IICE-FFyL-UBA. Email: lidiamero@filo.uba.ar
} 
DOI: $10.12957 /$ e-mosaicos.2017.31698

Palavras-Chave: Educação popular; Saberes; Alfabetização: História da educação

\section{INTRODUCCIÓN}

Sin duda el pensamiento de Paulo Freire sigue siendo una cantera donde abrevar en la búsqueda de propuestas educativas sustentadas en lógicas de justicia e igualdad, y un apoyo insustituible en la búsqueda de propuestas para plantear alternativas viables en el contexto del avance del modelo mercantilista y conservador en el continente.

Una perspectiva particularmente potente para abordar la obra del pedagogo brasileño es la de bucear en sus fronteras, sus tensiones internas, los debates que enfrentó.

En este trabajo abordamos uno de esos puntos, que ha atravesado los debates de la educación popular. Se podría plantear de modo sintético como la tensión entre dos horizontes de transformación del espacio educativo: el que pone el énfasis en el reconocimiento y jerarquización de los saberes populares; y el que se ubica más en la lógica de la educación moderna, que enfatiza la distribución del conocimiento socialmente acumulado. También podría ubicarse esa tensión como la que existe en dos categorías freireanas: "diálogo", que se sostiene en un planteo de igualdad radical; y "concientización", donde permanece una cierta asimetría del vínculo educativo. (Aunque no es el tema para profundizar en este trabajo, es necesario mencionar de todos modos que Freire relativiza el uso de este último término en los años 70). Dicho de otra manera, y aun a riesgo de simplificar, pero a favor de la claridad, se puede plantear la tensión entre el respeto de la cultura del educando, por una parte, y, por otra, la acción pedagógica para su transformación. Son temas riquísimos y complejos, que se pueden abordar desde múltiples perspectivas. Para aportar algunos elementos analizamos aspectos de un debate específico: el que se sostuvo en Guinea Bissau sobre la lengua en que debía realizarse la alfabetización.

\section{Freire en Guinea Bissau}

Guinea Bissau logró la independencia del dominio portugués después de una larga y dura guerra de liberación en 1974. La organización del nuevo estado fue un desafío enorme, dadas las terribles condiciones en que el domino portugués sostuvo su permanencia en el territorio, y el estado de pobreza general en que lo dejó y en particular respecto al tema educativo. Un $99 \%$ de la población era analfabeta en los años de 1960 (Pereira, 1976).

El nuevo país liberado se encontró con el enorme desafío de reestructurar el viejo sistema educativo, que atendía a un porcentaje mínimo de población, y generar con urgencia políticas inclusivas. 
Una de las acciones más importantes fue la organización de una Campaña de Alfabetización, tarea que fue característica por otra parte de esa época, que se desarrolló en muchos países del por entonces llamado "Tercer Mundo".

El gobierno de Guinea Bissau solicitó apoyo a Paulo Freire para esa tarea, formalmente en 1975, momento en se encontraba exiliado en Ginebra trabajando para el Consejo Mundial de Iglesias.

Uno de los problemas más importantes que tuvieron que enfrentar fue la decisión respecto a la lengua de la alfabetización. Se complejizaba mucho el tema en un país donde el $80 \%$ de la población de no hablaba portugués, el idioma de la administración.

Concretamente, "La lengua franca de los distintos grupos étnicos del país es el criollo, una mezcla de los dialectos portugués y africano" (GOULET, 1978, p. 31). Esa discusión se conoció mucho después. Decía Freire: "... pensé que el momento no era oportuno debido a cuestiones políticas de mayor trascendencia" (FREIRE \& MACEDO, 1989 , p. 121).

El equipo del IDAC proponía alfabetizar en "creole", o "criollo", que consideraban venía desempeñando un papel central en la unidad nacional. (FREIRE, Cartas a Guinea Bissau. Apuntes de una experiencia pedagógica en proceso, 1986, p. 171). Pero la decisión del Comisario de Educación, Mário Cabral, que fue la que finalmente se implementó, fue la de hacerlo en portugués.

En una carta fechada en julio de 1977 (y que se publicó más de 10 años después) Freire manifestaba que "el portugués terminará generando una división social en el país, creando una pequeña y privilegiada minoría urbana, opuesta a la mayoría oprimida del pueblo" (FREIRE, 1989, p. 164).

Por ello recomendaba el esfuerzo de producir la escritura del "criollo". Se sostenía en los planteos de Amílcar Cabral, el líder de la guerrilla guinense, intelectual importantísimo que el pedagogo brasileño admiraba mucho.

Cabral señalaba la des africanización de grupos urbanos que asimilan la cultura y la lengua dominante, con el correspondiente enajenamiento cultural. $Y$ rescataba a las grandes mayorías campesinas que encuentran en la preservación de su cultura un modo de sobrevivencia y de defensa frente a la agresión colonial.

La liberación no se da si ese pueblo no reconquista su palabra, "el derecho de decirla, de 'pronunciar' y de 'nombrar' el mundo". Es necesario que cada "hablante libere consigo su lengua de la supremacía de la lengua dominante del colonizador" (FREIRE, 1989, p. 168).

Los colonizadores niegan la existencia de historia y cultura en los pueblos colonizados, como un medio más de colonización.

Como sabemos, para Paulo Freire, el lenguaje elegido fue el principal problema para el no éxito de la Campaña. Aceptó esa decisión por respeto a la conducción política. 
Como extranjero, no podía imponer mis propuestas sobre la realidad y las necesidades que percibían los líderes políticos. La cuestión lingüística, por ejemplo, era uno de los límites que no podía traspasar, si bien discutí detallada e insistentemente con los educadores mi preocupación en torno al hecho de desarrollar la campaña de alfabetización en el idioma colonialista. Sin embargo, los líderes consideraban que resultaba políticamente beneficioso adoptar la lengua portuguesa como medio principal de la campaña de alfabetización (FREIRE \& MACEDO, 1989, p. 114).

En consonancia con esa postura, sostiene R. M. Torres que "aquellos que participaron de cerca en la experiencia de alfabetización de adultos consideran un error haber elegido el portugués" (TORRES, 1997, p. 117).

Mário Cabral manifiesta en otra carta muy posterior, muy afectuosa, que le envía a Freire 10 años después, las dificultades en la Campaña:

Si no fuera por la inexistencia del dialecto portugués en África y el desconocimiento absoluto del portugués en el medio rural, estoy seguro, habría tenido gran éxito, tal era la disposición política y la receptividad popular.... Si el criollo comienza a disponer de los elementos necesarios a su uso en la enseñanza, queda el problema de que el portugués continúa siendo la lengua oficial y de enseñanza (CABRAL, 1996, p. 115).

Desde la perspectiva de Freire el aprendizaje de la lecto escritura está en estrecha relación con la construcción de subjetividades políticas y no se reduce a un sistema gráfico. Refiriéndose años más tarde a la experiencia africana, replantea la concepción de la alfabetización como una relación dinámica entre "la lectura de la palabra y la 'lectura' de la realidad" (FREIRE, La importancia de leer y el proceso de liberación, 1992, p. 127).

En el marco de sociedades en procesos de transformación socialista, esta lectura de la realidad no era ingenua ni épica.

La "participación crítica y democrática de los educandos en el acto de conocimiento del que también son sujetos" exige "una comprensión crítica del momento de transición revolucionaria en que se halla el país" (FREIRE, La importancia de leer y el proceso de liberación, 1992, p. 129). La tarea de rehacer la sociedad exige que también el pueblo se rehaga a sí mismo. Lo cual conlleva una nueva concepción de la política, comprendiendo que "Hacer la historia es estar presente en ella, y no simplemente estar representado en ella" (FREIRE, La importancia de leer y el proceso de liberación, 1992, p. 131). 
Para ello es necesaria una alfabetización "formadora y no esologanizante" (FREIRE, 1992, p. 131).

Tanto la alfabetización tradicional como una que no plantee "el problema de la participación política del pueblo en la reinvención de su sociedad... estaría contribuyendo a que el pueblo estuviera simplemente representado por su historia" (FREIRE, 1992, p. 132).

\section{REPENSANDO LA DISCUSIÓN}

Muchas cosas han cambiado desde aquellos años. Sin embargo, es interesante indagar acerca de este debate en un continente como el latinoamericano, mosaico de culturas diversas, donde las prácticas orales y el uso de una enorme cantidad de idiomas originarios mantienen vigencia e influencia, a la vez que surge una "oralidad secundaria" alentada por los medios masivos y la computadora (RIVERO, 2009, p. $X X X)$.

De todos modos, es evidente que la cuestión no puede plantearse de modo dicotómico, y que abre un campo problemático complejo de discusión.

Elegimos entonces trabajar, indagando y en todo caso interpretando acerca de los supuestos que sostienen los diferentes planteos.

\section{LA POSICIÓN DE FREIRE}

¿Cuáles son los supuestos de la posición de Freire que vinculan "la escritura de la realidad" a la lengua "materna"?

Por lo menos señalamos dos: es en el idioma materno donde se aloja la posibilidad de la liberación, lo cual supone a la vez la existencia de lenguas "puras".

Es la "posesión" de esa lengua "materna" la que permite distinguir las identidades. Es por la lengua que se diferencian unos pueblos de otros, por ello conservarla es conservar también la pertenencia a una comunidad. Por lo mismo, la lengua es solicitada como un lugar de reconocimiento, en todo caso como el último refugio, el espacio de una singularidad irreductible a toda dominación (CRÉPON, 2005).

Tal postura se fundamenta en la certeza de la posibilidad de establecer límites precisos entre lenguas que serían homogéneas y claramente diferenciadas. Esta complejidad se plantea de modo paradigmático en Guinea Bissau, conformada por una diversidad de etnias con diferentes lenguas (Balantes, Foulas, Manjacas, Mandingas, Papeis, Brames, Bijagos). La propuesta freireana implicaba un esfuerzo de reducción de esa diversidad al "criollo", que si bien era hablado por la mayoría no correspondía a las lenguas originarias de las comunidades. Por otra parte, siguiendo el planteo freireano, el criollo estaba fuertemente "contaminado" con el portugués. 
DOI: $10.12957 /$ e-mosaicos.2017.31698

De todos modos, más allá de la particular situación en el país africano, la pregunta es acerca de la posibilidad misma de un idioma "puro" (DERRIDA, 1996).

Otro supuesto central es que es esa lengua materna la que permite pronunciar una palabra "propia" que sería emancipada. Ese punto debería ser replanteado: así como la pertenencia, es también en la lengua materna donde se experimenta la radical extranjeridad (CRÉPON, 2005). Pero sobre todo es importante tener en cuenta que es también en la lengua materna donde se aprende la dominación: "Piel negra, máscaras blancas" decía Fanon para dar cuenta de la compleja psicología del oprimido y los efectos psicotizantes de la opresión.

Siguiendo a ese autor, Freire plantea que la identidad del sujeto latinoamericano está dada en su "opresión", se trata de un sujeto "dual", que se reconoce en la identidad del opresor. "Los oprimidos son "seres duales, inauténticos, que "alojan" al opresor en sí ..." (FREIRE, 2002, p. 35).

¿Cuál sería entonces la garantía de que es en ese universo cultural donde se encuentra el germen emancipatorio?

\section{La posición de Cabral}

Por otro lado, ¿desde qué supuestos el equipo de Cabral proponía la enseñanza del idioma del colonizador?

En primer lugar, considera que es la apropiación de la lengua "colonial", que se ha tornado "global", la que abre un camino emancipatorio. Ella da acceso a la administración, al aparato del estado y a la universidad pública. Esta posición parecería reducir el problema de la lengua y la alfabetización a su función instrumental y en ese sentido comunicativo.

Pero por otra, el gobierno guinense está más preocupado por un contexto más amplio que el local, de nivel internacional, donde la lengua del colonizador permitía otros intercambios y luchas de poder. ¿No había estudiado Cabral en Lisboa, y expuesto sus planteos en los foros internacionales muchas veces en inglés y francés? Como metáfora, los "Subaltern Studies" se desarrollan en India y se expanden a nivel internacional en un idioma global, inglés, que fue también del colonizador.

Desde esa perspectiva, el triunfo revolucionario estaba más ligado a la posibilidad de mejoras rápidas en la vida de las personas, que sumara voluntades y permitiera una consolidación hegemónica del nuevo gobierno. Era el acceso al portugués el camino más rápido para esos objetivos.

\section{EN SÍNTESIS}

La alfabetización en lengua "materna" no resuelve ni contribuye de modo evidente la problemática de la vinculación entre alfabetización -en el sentido general de "lectura de la palabra, lectura de la realidad"- y emancipación. 
Se pueden poner en discusión algunos supuestos que fundamentan esa posición: la posibilidad de homogeneidad de la lengua, su centralidad en la construcción de la identidad, sus fronteras claras respecto a la dominación.

Tampoco la propuesta de apropiación de la lengua del colonizador resuelve completamente la cuestión, sobre todo porque tal posición reduce la lengua a su función instrumental.

La lengua es sin duda uno de los anclajes más sólidos de la identidad de un pueblo, por lo cual estas discusiones no se circunscriben al problema de la alfabetización, sino que remiten al plano más general de la cultura. Desde esta perspectiva, la discusión sobre la lengua de la alfabetización es sólo una dimensión de un campo problemático más complejo que podríamos ubicar como el de "contacto cultural". Alicia de Alba lo define como

intercambio de bienes culturales y la interrelación entre grupos, sectores o individuos de distintas culturas y, por tanto, con diferentes códigos semióticos y manejo y uso de signos (significantes y significados) que producen cambios en los distintos sujetos que participan de él y en sus contextos (de ALBA CEBALLOS, 2002, p. $x x x)$.

En fin, en la línea de aportar reflexiones para un trabajo alfabetizador y educativo en general, en el marco de un proyecto emancipatorio, señalamos a modo de síntesis:

- El problema planteado de un modo dicotómico -lengua materna, lengua hegemónica- invisibiliza una cuestión que Freire conocía bien: los vínculos entre alfabetización y emancipación son distantes, indirectos y complejos. Él decía, por ejemplo: "una cosa es trabajar en el seno de las FARP (Fuerzas Armadas Revolucionarias del Pueblo), ... y ora cosa es trabajar en los barrios populares de Bissau, .... fuertemente marcados ... por la ideología colonialista. ..." (FREIRE, 1986, p. 42).

- Más que por el camino de una identidad ya presente a la que daría acceso y consistencia la lengua materna, la subjetividad emancipada se requeriría la desafiliación a una lengua única, homogénea y "pura". Se trata de un proceso pedagógico profundamente vinculado a la praxis, donde el acceso a otra lengua facilita la invención de palabras, lecturas distintas de la realidad, abre otros horizontes (CRÉPON, 2005).

- El planteo freireano soslaya un componente evidente, en particular en el nuevo milenio: lo colonial se ha tornado "universal", y ofrece no solo la posibilidad de redes, comunicaciones, ámbitos no accesibles desde el plano de lo local, sino también el acceso a horizontes de sentido que pueden contribuir en la configuración de nuevas discursividades con capacidad de disputa 
hegemónica. En esa lógica es útil distinguir en la lengua sus dimensiones locales, coloniales y globales (IVEKOVIC, 2007).

El universalismo de una lengua global es solo una operación de hegemonía de un cierto particular, es un proceso por el cual la lengua colonial se mundializa. Sin embargo, como parte de esa construcción, ha logrado cierto grado de "neutralidad". No sólo permite intercambios en el espacio a los que no tienen acceso a las lenguas locales, sino permite la articulación de los planos local y global.

Esa característica no elimina la característica de lengua "colonial" en el sentido de Fanon, es decir, de ser no solo la lengua del "opresor" sino de aquella en la cual el "oprimido" ha construido una identidad "dual", dividida, que obstaculiza su proceso de "humanización". Más bien es la que le abre un espacio donde disputar otra construcción social de sentido. La lengua "local", lengua "materna", cargada también de historia para los hablantes, tiene el peligro potencial de encerrarlos en un territorio desde el cual no se puede construir vocabulario para un proceso emancipatorio.

- En esa lógica se ubica la aporía de la identidad oprimida: reafirmarse es reafirmar su opresión. Defender su identidad la socava, si se trata sólo de una ratificación de lo que ya es.

- La identidad de un pueblo no es reductible al espacio de "una" lengua. Por el contrario, "La lengua surge cuando se suspende la comunicación imediata" (CRÉPON, 2005).

Por el contrario, existe un espacio incomunicable, lo que no puede ser dicho, que es experiencia histórica común no siempre construida como relato 0 conocimiento.

- Es en esa historia vivida, en la memoria como experiencia, donde un proyecto emancipatorio encuentra fuerza y fundamento. Las decisiones respecto a la alfabetización requieren ser articuladas a una prospectiva donde se ubique la construcción de ese sujeto -proyecto en ese horizonte de sentido y con esa direccionalidad (ZEMELMAN MERINO, 1992; 1998).

No sólo la lengua materna es sustantiva, también la lengua hegemónica tiene un lugar desde el cual pueden aportar a ese proceso. Pero también es importante tener en cuenta que en el trabajo pedagógico en un proyecto emancipatorio cuenta también tener en cuenta de modo central los procesos populares de elaboración de un trabajo de memoria, articulada a la historia reciente.

En la historia latinoamericana en particular, un proceso que facilitara el atravesamiento del trauma, la recuperación del silencio, la habilitación del recuerdo y su puesta en palabras. Ello requiere apertura a otros universos culturales, a lenguas globales, a territorios más vastos que el local. 
DOI: $10.12957 /$ e-mosaicos.2017.31698

\section{REFERÊNCIAS BibLIOGRÁfICAS}

CABRAL, M. Carta. Bissau, 10 de junio de 1985. En: GADOTTI, M; TORRES, C. Paulo Freire: Una biobibliografía. São Paulo: Cortez, UNESCO, IPF, 1996.

CRÉPON, M. Aimer sa langue autrement. En h. noviembre (Ed.), Colloque Derrida, la tradition de la philosophie. Paris: École Normale Supérieure, 19 julio 2005.

. Langues sans demeure. Paris: Galilée, 2005.

DE ALBA CEBALLOS, A.. Educación: contacto cultural, cambio tecnológico y perspectivas postmodernas. En: BUENFIL BURGOS, R. N.. En los márgenes de la educación: México a finales del milenio. México: SAPD-PyV, 2002.

DERRIDA, J.. El monolinguismo del otro. Buenos Aires: Manantial, 1996.

Freire, Paulo. Cartas a Guinea Bissau. Apuntes de una experiencia pedagógica en proceso. México: Siglo XXI, 1986.

. La importancia de leer y el proceso de liberación. México: Siglo XXI, 1992.

. Pedagogía del Oprimido. (S. XXI, Ed.) Buenos Aires, Argentina: Siglo XXI, 2002.

. Carta a Mário Cabral. 15 de julio 1977. En Freire, Paulo; MACEDO, D. Alfabetización. Lectura de la palabra y lectura de la realidad. Barcelona, Buenos Aires, México: Paidos, 1989.

; Macedo, D. Alfabetización. Lectura de la palabra y lectura de la realidad. Barcelona, Buenos Aires, México: Paidos, 1989.

GOULET, D. Looking at Guinea Bissau: A new Nations Develpment Strategy. Overseas Development Council. Ocassional papers.(9), 66pp. Citado en: TORRES, Carlos A.: A voz do biógrafo latino-americano. Una biografía intelectual. En: GADOTTI, M. Paulo Freire, una biobibliografía. Cortez, UNESCO, IPF. Sao Paulo, 1996.

IVEKOVIC, R. Langue coloniale, langue globale, langue locale. Reflexions sur la postcolonie. Rue Descartes.(58), 2007.

PEREIRA, A.. Balanco de 20 anos de luta pela libertacao da Guiné e de Cabo Verde. Discours deu secrétaire general du Parti, lors de la session solennelle de commémoration du 20a anniversaire du PAIGC, Bissau, le 19 septembre 1976. En: L. Rudebeck, Guinea Bissau: a study in political mobilization. Uppsala: Scandinavian Institute of African Studies, 1976, p. 15-19.

RIVERO, J. Concepciones y ejecución de políticas en la educación con personas jóvenes y adultas. México: CEAAL, Ed. La Piragua, II(29), 2009.

TORRES, Carlos. A voz do biógrafo latino-americano. Una biografía intelectual. En: GADOTTI, M. Paulo Freire, una biobibliografia. Sao Paulo: Cortez, UNESCO, IPF, 1996. 
e-Mosaicos - Revista Multidisciplinar de Ensino, Pesquisa, Extensão e Cultura do Instituto de Aplicação Fernando Rodrigues da Silveira (CAp-UERJ)

V. 6 - N. 13 - DEZEMBRO 2017 - ISSN: 2316-9303

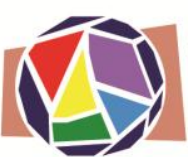

DOI: $10.12957 /$ e-mosaicos.2017.31698

ZEMELMAN MERINO, H.. Los horizontes de la razón. México: Antrophos, 1992.

ZEMELMAN, H.. Sujeto: existencia y potencia. México: Anthropos-Colegio de México, 1998.

Recebido em 15 de outubro de 2017.

Aceito em 04 de novembro de 2017. 